\title{
UCRL-PROC-217746
}

LAW RENCE LIVERMORE N A T IO N A L LABORATORY

\section{Oxidation of uranium nanoparticles produced via pulsed laser ablation}

T. W. Trelenberg, S. C. Glade, J. G. Tobin, T. E. Felter, A. V. Hamza

December 15, 2005

Materials Research Society Fall Meeting Boston, MA, United States November 28, 2005 through December 2, 2005 
This document was prepared as an account of work sponsored by an agency of the United States Government. Neither the United States Government nor the University of California nor any of their employees, makes any warranty, express or implied, or assumes any legal liability or responsibility for the accuracy, completeness, or usefulness of any information, apparatus, product, or process disclosed, or represents that its use would not infringe privately owned rights. Reference herein to any specific commercial product, process, or service by trade name, trademark, manufacturer, or otherwise, does not necessarily constitute or imply its endorsement, recommendation, or favoring by the United States Government or the University of California. The views and opinions of authors expressed herein do not necessarily state or reflect those of the United States Government or the University of California, and shall not be used for advertising or product endorsement purposes. 


\section{Oxidation of uranium nanoparticles produced via pulsed laser ablation}

Thomas.W. Trelenberg, Stephen.C. Glade, James.G. Tobin, Thomas E. Felter, and Alex.V. Hamza

Chemistry and Materials Science Directorate, Lawrence Livermore National Laboratory Livermore, CA 94551, U.S.A.

\section{ABSTRACT}

An experimental apparatus designed for the synthesis, via pulsed laser deposition, and analysis of metallic nanoparticles and thin films of plutonium and other actinides was tested on depleted uranium samples. Five nanosecond pulses from a Nd:YAG laser produced films of $\sim 1600 \AA$ thickness that were deposited showing an angular distribution typical thermal ablation. The films remained contiguous for many months in vacuum but blistered due to induced tensile stresses several days after exposure to air. The films were allowed to oxidize from the residual water vapor within the chamber $\left(2 \times 10^{-10}\right.$ Torr base pressure). The oxidation was monitored by in-situ analysis techniques including x-ray photoelectron spectroscopy (XPS), ultraviolet photoelectron spectroscopy (UPS), and scanning tunneling microscopy (STM) and followed Langmuir kinetics.

\section{INTRODUCTION}

Surface science studies of actinide electronic structure should ideally be carried out on clean, single-crystalline samples, however, producing these large samples has proven difficult. Bandmapping requires that the orientation of the crystalline facet under measurement be known. At the same time, the probe used must not extend beyond this facet or to neighboring crystallites. While efforts to grow larger, single-crystal actinide samples have met with some success, isolation of these crystals for study via traditional techniques can still be difficult.

Another approach is to study thin films grown on suitable substrates. Crystalline films may be produced in this way; however, the observed structure may have substrate influences present and care must be taken to ensure that these influences are taken into account.

Our approach was to attempt to isolate and analyze laser ablated nanocrystallites using microprobe techniques. A film would be ablated onto a substrate, verified clean with photoemission (XPS an UPS), crystallite location and orientation determined using standard STM, and finally probing electronic structure using STS (scanning tunneling spectroscopy). To this end, we have constructed an experimental apparatus designed for the synthesis and analysis of metallic nanoparticles and thin films of plutonium and other actinides [1,2]. Pulsed laser ablation was chosen as the method for producing our samples, as the production of both highpurity nanoscale material [3] and actinide films [4] (through careful annealing) have been demonstrated. Laser ablated nanocrystallites naturally occur with a range of sizes, so further processing, other than choosing a particle size via an STM scan, would not be required.

One of the chief challenges we faced was to deposit actinide material that contained no oxide. The high reactivity of the actinide elements makes this a challenging task. Oxide free surfaces have been prepared via sputter-cleaning of the surface $[5,6]$, laser ablative cleaning of the surface [6], and plasma deposition [7,8]. The availability of compact, relatively low-cost, high-power pulsed laser systems may now allow laser deposition to emerge as a competing technology. Laser ablation inherently produces nanoscale material, has demonstrated the 
transference of the stoichiometry of a large number of complex target materials to sample substrates $[3,9,10,11,12]$ provided certain conditions are met [13].

Initial experiments were preformed with depleted uranium. Depleted $U$ has a lower activity and toxicity than plutonium, allowing us to more easily test the different components of the experimental apparatus. In this paper, we present our observations on the deposition and oxidation of these depleted $\mathrm{U}$ nanoparticles.

\section{EXPERIMENTAL DETAILS}

The driving design requirements of the experimental apparatus were (1) that the total amount of actinide used must be minimized and (2) that the vacuum vessels themselves serve as containment vessels. A detailed description of the experimental apparatus is given in Ref. 2. Briefly, metallic nanoparticles of an actinide are deposited onto a 13 x $13 \mathrm{~mm}$ substrate ( $\mathrm{Si}$ wafers and Au-coated Si wafers) via pulsed laser deposition in a sample preparation chamber (1 $-3 \times 10^{-10}$ Torr). Frequency-doubled $532 \mathrm{~nm}$ light from a Nd:YAG laser irradiated the targets with $5 \mathrm{~ns}$ pulses at a repetition rate of $10 \mathrm{~Hz}$. Laser power ranged from 0.13 to 0.32 watts with a visible spot size (damage area) of $\sim 1.25 \times 2 \mathrm{~mm}$ remaining on the target following ablation. Initially a small number of shots for both cleaning and ablation (3-60 shots) were carried out at relatively high laser powers (1-4 watts at $532 \mathrm{~nm}$ ), but produced highly oxidized surfaces. Reduced oxidation was observed when utilizing a larger number (thousands) of lower power shots (0.25-0.15 watts). A 0.2 optical density filter ( $63 \%$ transmission) was placed in the beam during deposition such that the ablation threshold for the deposition would be well inside that which had existed during the cleaning shots.

After production of a sample, the substrates were analyzed in-situ using XPS, UPS, and STM. Other analyses presented we performed once the sample had been removed from the vacuum chamber and been exposed to air.

\section{RESULTS}
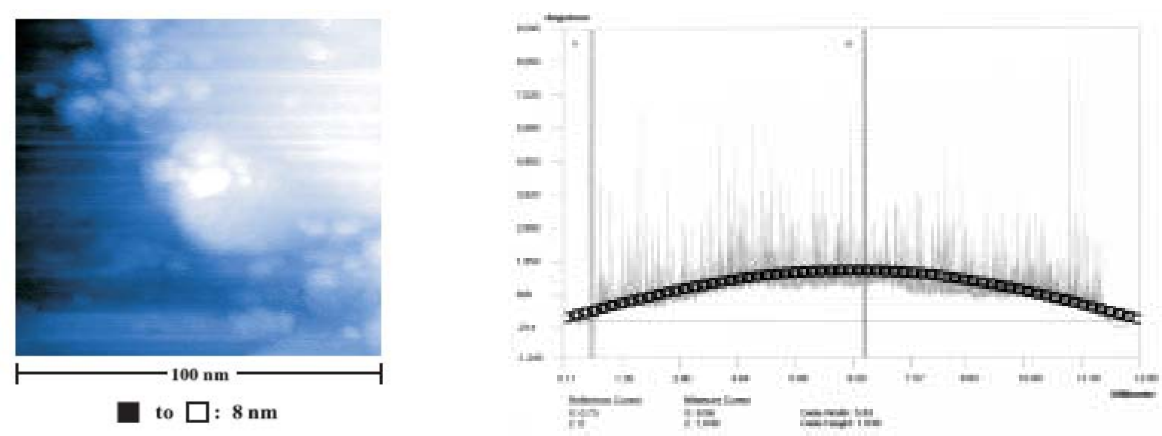

Figure 1. STM of the deposited material shows (left) the nanostructural nature of the material deposited with laser ablation. Profilometry shows the film to be $\sim 1600 \AA$ thick with an angular distribution $(\cos \theta)$ consistent with a completely thermal ablation (no fast effects). The film was deposited using 27000 pulses at 0.25 watts through a 0.2 neutral density filter.

Figure 1 shows the in-situ STM of the deposited material as well as the profilometry of the deposited film following its removal from the system. The STM image reveals a large 
number of nanoparticles with a substantial variation in size. Once the material can be produced without oxidation, these particles can be studied with STS and the influence of quantum confinement effects may change the observed electronic structure as a function total particle size. We had anticipated that, due to quantum confinement effects and surface morphology (Figure 2 left), the laser produced film would have different oxidation characteristics than a sputter cleaned (argon) uranium film. However, both films oxidized from the residual gases of the vacuum chamber in a similar manner. The films coated the substrate nicely, without visible holes and maintained their integrity throughout the oxidation analysis. However, after removal from the system and exposure to air, tensile stresses would begin building up in the films, eventually causing them to blister as seen in Figure 2 (right).
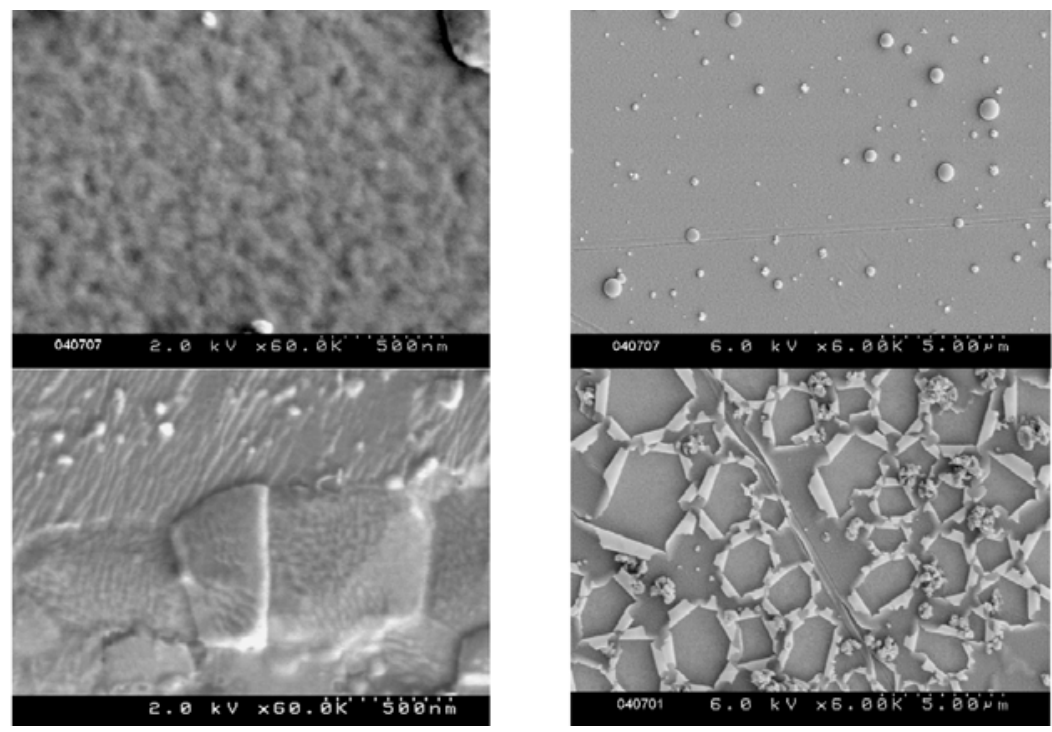

Figure 2. SEM of the deposited material shows (top left) shows a very different morphology from that of a sputter cleaned foil (bottom left). A three month old film (top right) remains contiguous immediately following air exposure, but blisters due to tensile stresses building up in the film during prolonged exposure (two months).

Before any analysis of the oxidation could begin, a reliable method for the laser deposition of a clean uranium film needed to be found. Our first efforts resulted in films that were completely oxidized, but with time, we were able to refine the technique such that clean films could be produced (Figure 3 ). Initially, with a confined ablation (see Ref. 2), a low number (tens) of high-power shots (1-4 watts), and no pre-cleaning, we produced a film that was completely oxidized. Cleaning shots were then introduced, in which the target was ablated without the substrate present in order to prevent deposition on the substrate of material from an aged surface of the target material, and this resulted in an improved deposition. We then moved to a deposition of consisting of a large number (tens of thousands) of low-power (0.15-0.25 watts), which lead to further improvement. An improvement of the cleaning procedure, introduced the addition of a 0.2 (63\% transmission) optical density neutral density filter into the beam line for the actual deposition following the initial cleaning shots. This allowed the ablation threshold of the to deposition pulses terminate to be well within the area cleaned (ablation threshold) of the cleaning shots. While this was sufficient to eliminate oxidation measurable by our XPS (U4f and O1s), initial oxidation was still detectable with a measurement taken at the 
more sensitive valence level with UPS. This final trace of oxidation occuring in the deposited films was only eliminated when the confinement apparatus (Ref. 2) were removed. While the removal of this feature allowed the deposition of a film shown to be oxygen free via UPS, it also eliminated our capability to guarantee that the uranium deposition was constrained to the substrate.
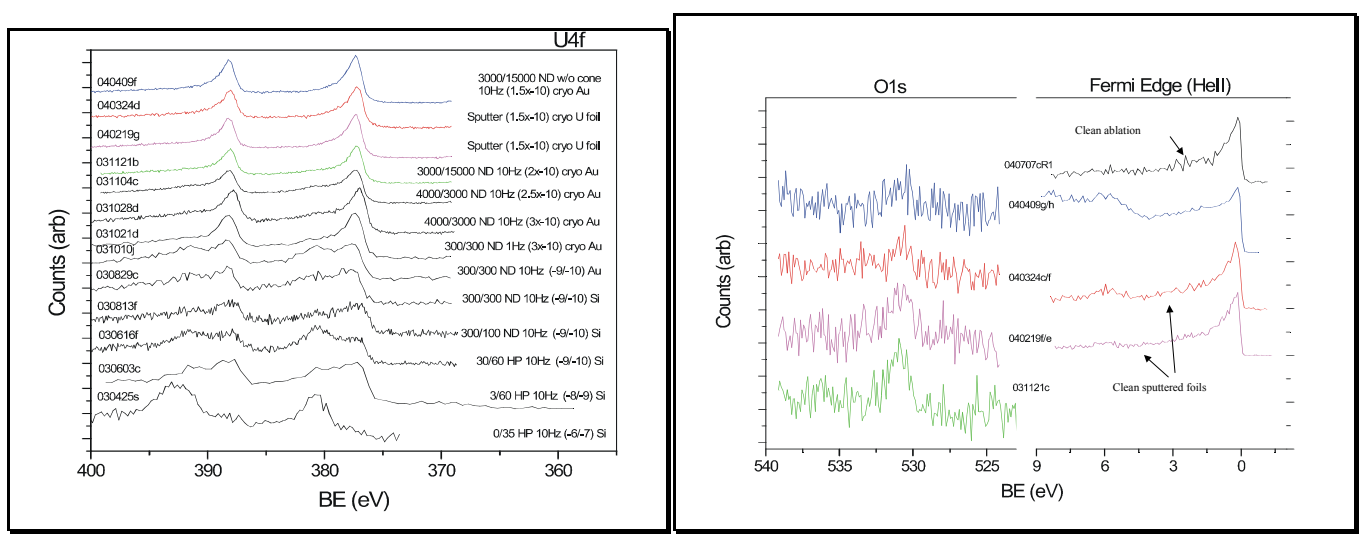

Figure 3. Summary of the path to the finding the procedure for deposition of a clean actinide film using pulsed laser ablation. The first sample was shown to by XPS to be completely oxidized (bottom spectrum in left pane) but with time, laser ablation was able to produce films as clean as any shown in the literature or obtained by sputtering (upper right-most spectrum in right pane).
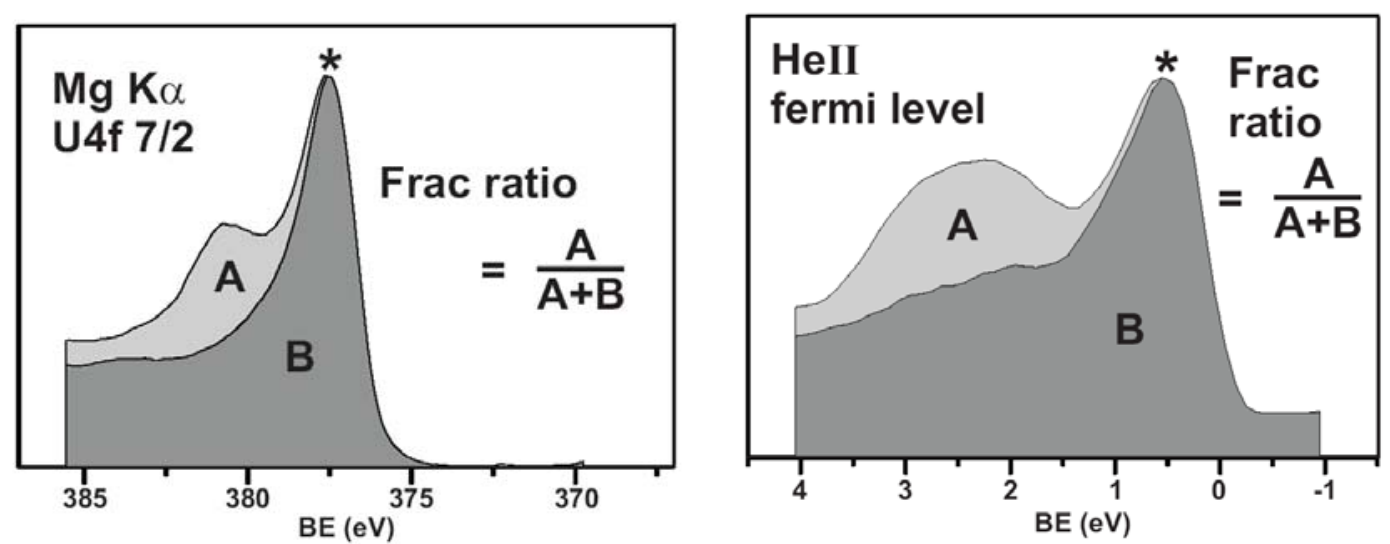

Figure 4. Schematic illustrating the procedure used to determine the fractional ratios of oxidized uranium photoemission spectra. An example for the core level U4f $7 / 2$ peaks obtained from XPS is shown on the left while and example from the Fermi level UPS is shown on the right.

Once we had produce clean material, the task of quantifying the oxidation process remained. A number of attempts were made to get an absolute value for the amount of oxidation at various stages, by attempting the conventional peak fittings of the U4f uranium metal peaks (377.2 eV binding energy) and the $\mathrm{O} 1 \mathrm{~s}$ peak $(531.6 \mathrm{eV})$. However, the fitting parameters resulting in a good fit varied significantly over the course of the oxidation from uranium metal to oxide and it was found that user choices in adjusting to these variations lead to unacceptably 
large variations in oxidation level and subsequent re-analysis of the same data sets lacked any sort of repeatability.

Failing to find an acceptable absolute quantification method for the amount of oxidation, we finally chose a more relative determination that was repeatable and self-consistent. This method utilized the clean metal spectrum (obtained immediately following deposition) to analyze the subsequent oxidized spectra. This method is illustrated in Figure 4.

When analyzing an oxidized spectra (area A+B in Figure 4) the clean metal scan (area B) has the amplitude of its metal peak scaled to the amplitude of the metal peak in the oxidized spectra. The areas are then subtracted to obtain area $A$ (the change from $B$ occurring due to oxidation). $\mathrm{A}$ is then divided by the total area of the oxidized scan $(\mathrm{A}+\mathrm{B})$ to give the fractional ratio of oxidation, ranging from $0 \%$ (clean metal) to $100 \%$ (only oxide is detected down to the depth of scan). The results of following this analysis procedure on a data set that began with clean metal and ended when metal character could no longer be detected is shown in Figure 5 (left).
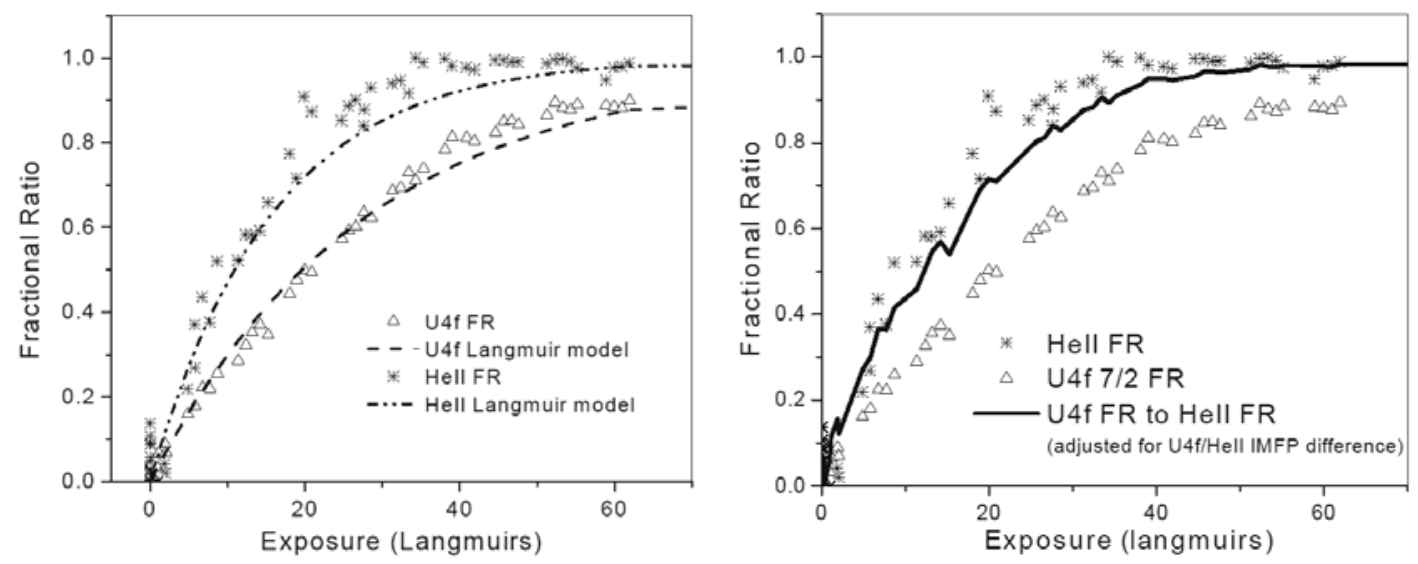

Figure 5. Plots of U4f and Fermi level fractional ratio data along with the results expected for each from the Langmuir model (left pane). The right hand figure shows the same data (points) as well as the U4f fractional ratio data corrected for the difference in the depth of scan between the $\mathrm{MgK} \alpha$ radiation used to scan the core levels and the HeII radiation used to scan the valence levels. 1 Langmuir $=10^{-6}$ Torr-sec

A number of 2-D and 3-D nucleation-and-growth and diffusion models were used to attempt to fit the data provided by the fractional ratios, however, it was the simple 2-D Langmuir model that provided the best fit. That such a simple 2-D surface growth model should describe our data so well indicates that, on the timescale of our observation, oxygen binds with the surface, but that there is little penetration into the bulk. Additionally, using surface sensitive photoemission techniques it will be very difficult to follow diffusion as it will be masked by the large oxygen signal from the surface.

Also shown in Figure 5 (right) is the U4f data replotted once the difference between the depth of scan for the XPS and UPS irradiation regimes are taken into account. The similarity of the replotted U4f data to the UPS data shows that, using the fractional ratio method, valence level data can be used to determine the amount of oxidation present without the need to obtain core level (U4f) data solely for this purpose. 
An expanded discussion of these results is expected to appear in an upcoming Surface Science article.

\section{ACKNOWLEDGEMENTS}

This work was performed under the auspices of the U.S. Department of Energy by University of California Lawrence Livermore National Laboratory under contract No. W-7405Eng-48.

\section{REFERENCES}

1. S.C. Glade, T.W. Trelenberg, J.G. Tobin, P.A. Sterne, and A.V. Hamza in Plutonium Futures-The Science, ed. G.D. Jarvinen (AIP Conf. Proc. 673, Melville, NY, 2003) pp. 148149.

2. T.W. Trelenberg, S.C. Glade, T.E. Felter, J.G. Tobin, and A.V. Hamza, Rev. of Sci. Inst., 75, 713 (2004).

3. D.B. Chrisey and G.K. Hubler, eds., Pulsed Laser Deposition of Thin Films, (WileyInterscience, New York, 1994).

4. R. J. Tench, "The nucleation and growth of uranium on the basal plane of graphite studied by scanning tunneling microscopy", Ph.D. thesis, University of California, Davis, report number: UCRL-LR-112417 (1992).

5. T. Gouder, C. Colmenares, J. Naegele, J. Verbist, Surf. Sci. 235 (1989) 280-286.

6. J. J. Joyce, A. J. Arko, L. A. Morales, Los Alamos Science 26 (2000) 186-187.

7. T. H. Gouder, C. A. Colmenares, Surf. Sci. 341 (1995) 51-61.

8. T. Gouder, Surf. Sci. 382 (1997) 26-34.

9. J. G. Lunney, Appl. Surf. Sci. 86 (1995) 79-85.

10. B. Dam, H. J. Rector, J. Johansson, S. Kars, R. Griessen, Appl. Surf. Sci. 96-98 (1996) 679-684.

11. T. W. Trelenberg, L. N. Dinh, C. K. Saw, B. C. Stuart, M. Balooch, Appl. Surf. Sci. 221/1-4 (2004) 364-369

12. L. N. Dinh, S. E. Hayes, A. E. Wynne, M. A. Wall, C. K. Saw, B. C. Stuart, M. Balooch, A. K. Paravastu, J. A. Reimer, J. Mater. Sci. 37 (2002) 3953-3958.

13. T. W. Trelenberg, L. N. Dinh, B. C. Stuart, M. Balooch, Appl. Surf. Sci. 229 (2004) 268274. 